\title{
Treatment of Antibiotic-Associated Clostridium difficile Colitis with Oral Vancomycin: Comparison of Two Dosage Regimens
}

\author{
ROBERT FEKETY, M.D., JOSEPH SILVA, M.D., CAROL KAUFFMAN, M.D., BRIAN BugGY, M.D., H. GuNNER
}

DEERY, M.D. Ann Arbor, Michigan

PURPOSE: High-dose (500 mg orally four times daily) vancomycin is considered by many investigators to be the most effective treatment for antibiotic-associated Clostridium difficile colitis. However, a lower dosage of 125 or $150 \mathrm{mg}$ given three or four times a day has become popular, has been shown to be effective, and is less expensive than the highdose regimen. We therefore decided to compare two vancomycin dosage regimens in a randomized trial.

PATIENTS AND METHODS: The study involved 46 hospitalized patients with serious underlying diseases complicated by $C$. difficile diarrhea or colitis. Patients were assigned (according to a table of random numbers) to treatment with either 125 or $500 \mathrm{mg}$ of vancomycin orally four times daily for an average of 10 days.

RESULTS: No significant differences in measurable responses to the two regimens were noted. There were no treatment failures. The mean duration of diarrhea after initiation of therapy was about four days, and almost all patients had no diarrhea after one week. The organism continued to be demonstrated in the stools of about 50 percent of patients for the first few weeks after completion of therapy, and nine ( 20 percent) patients developed a recurrence of their diarrheal illness. Vancomycin was well tolerated by all patients.

CONCLUSION: Since the dose of $125 \mathrm{mg}$ appeared to be as effective as the 500-mg dose, which is more expensive, the $125-\mathrm{mg}$ dose is preferred when vancomycin is used in treatment of this disease, unless the patient is critically ill.

\footnotetext{
From the Division of Infectious Diseases, the Department of Internal Medicine, The University of Michigan Medical Center, Ann Arbor, Michigan. This work was supported by a grant from the National Institutes of Health (NIAID \#21076) and by a grant from the Upjohn Company. Requests for reprint should be addressed to Robert Fekety, M.D., Division of Infectious Diseases, University of Michigan Medical Center, 3116 Taubman, 1500 East
Medical Center Drive, Ann Arbor, Michigan 48109-0378. Manuscript submitted June 30, 1988, and accepted in revised form October 27, 1988.
}

D iarrhea is a common and sometimes life-threatening side effect of antibiotic therapy. About 10 percent of hospitalized adults develop diarrhea after receiving antimicrobial drugs for treatment or prophylaxis of an infection. Some of these patients can be shown to have pseudomembranous colitis caused by toxins produced by Clostridium difficile [1]. Diagnosis of this complication is now relatively straightforward [2], and treatment consisting of supportive therapy, discontinuation of the precipitating antimicrobial drugs, and the oral administration of antimicrobial agents effective against $C$. difficile is usually successful in terminating the illness within a week [3]. Vancomycin given orally in a dosage of 500 mg four times daily has been considered by many investigators to be the most effective treatment for this disease [4]. However, vancomycin is expensive, often costing more than $\$ 400$ per week, and is not available in some parts of the world. Consequently, other forms of therapy have been evaluated and found to be effective, specifically metronidazole and bacitracin. Metronidazole given orally has been shown to be as effective as vancomycin in one controlled study [5]. However, metronidazole-resistant isolates of $C$. difficile have been detected, and treatment failures with it have been reported [5-7]. Resistance to bacitracin is common in our isolates of $C$. difficile [8], and in addition, treatment of the disease with bacitracin has not been shown to relieve symptoms as rapidly as vancomycin or to be as effective in eliminating the organism $[9,10]$. Consequently, vancomycin is still preferred by many for treatment of $C$. difficile colitis, particularly if the patient is severely ill. Since the stool concentrations achieved when vancomycin is given orally in a total daily dose of $2.0 \mathrm{~g}$ are many times those required to inhibit all isolates of $C$. difficile [1,11], a lower dosage of 125 or $150 \mathrm{mg}$ given three or four times per day has become popular. 'These so-called low-dose regimens have been shown to be effective [12], and have the obvious advantage of being much less expensive than the traditional regimen.

Since the use of low-dose instead of high-dose vancomycin regimens has been supported by uncontrolled studies and anecdotal case reports [3], we decided to compare the therapeutic efficacy of the low-dose and high-dose regimens in a controlled manner at our institution. The results of this study are the subject of this report.

\section{PATIENTS AND METHODS}

Patients with antibiotic-associated diarrhea at the University of Michigan Hospitals or the Ann Arbor Veterans Administration Hospital were considered for entry into the study after giving informed consent. 


\begin{tabular}{|c|c|c|c|}
\hline \multicolumn{4}{|c|}{$\begin{array}{l}\text { TABLE I } \\
\text { Distribution of Treated Patients }\end{array}$} \\
\hline \multirow[b]{2}{*}{ Diagnosis } & \multicolumn{2}{|c|}{ Oral Dose of Vancomycin* } & \multirow[b]{2}{*}{ Total } \\
\hline & $\begin{array}{l}125 \text { mg four } \\
\text { Times/Day }\end{array}$ & $\begin{array}{l}500 \text { mg Four } \\
\text { Times/Day }\end{array}$ & \\
\hline $\begin{array}{l}\text { Probable } C \text {. difficile colitis } \\
\text { Definite C. difficile colitis } \\
\text { Total patients }\end{array}$ & $\begin{array}{l}11(46) \\
13(54) \\
24(52)\end{array}$ & $\begin{array}{l}7(32) \\
15(68) \\
22(48)\end{array}$ & $\begin{array}{l}18(39) \\
28(61) \\
45(100)\end{array}$ \\
\hline
\end{tabular}

\begin{tabular}{|c|c|c|}
\hline \multicolumn{3}{|c|}{$\begin{array}{l}\text { TABLE II } \\
\text { Comparability of Treatment Groups }\end{array}$} \\
\hline Characteristic & $\frac{\text { Oral Dose }}{0.5 \mathrm{~g} / \text { Day }}$ & $\frac{\text { ncomycin }}{2.0 \mathrm{~g} / \text { Day }}$ \\
\hline $\begin{array}{l}\text { Number of patients } \\
\text { Mean age in years (range) } \\
\text { Mean number antibiotics } \\
\text { given prior to diärrhea }\end{array}$ & $\begin{array}{l}24 \\
56(1-74) \\
1.3\end{array}$ & $\begin{array}{l}22 \\
52(12-76) \\
2.2\end{array}$ \\
\hline $\begin{array}{l}\text { Number patients who received } \\
\text { cancer chemotherapy }\end{array}$ & 3 & 5 \\
\hline \multicolumn{3}{|l|}{ Types of underlying diseases } \\
\hline $\begin{array}{l}\text { Neoplasms } \\
\text { Definite infections }\end{array}$ & $\begin{array}{l}9 \\
6\end{array}$ & $\begin{array}{r}10 \\
7\end{array}$ \\
\hline $\begin{array}{l}\text { Chronic inflammatory } \\
\text { bowel disease. }\end{array}$ & 1 & 1 \\
\hline Diabetes mellitus & 1 & 3 \\
\hline $\begin{array}{l}\text { Recent surgery } \\
\text { (non-abdominal) }\end{array}$ & 5 & 4 \\
\hline $\begin{array}{l}\text { Abdominal diseases or } \\
\text { recent abdominal surgery }\end{array}$ & 11 & 13 \\
\hline Other & $\begin{array}{c}7 \\
40\end{array}$ & $\begin{array}{r}5 \\
43\end{array}$ \\
\hline
\end{tabular}

\section{TABLE III}

\section{Antimicrobials Associated Most Often with Diarrhea*}

\begin{tabular}{lc}
\hline \multicolumn{1}{c}{ Drug } & Number \\
\hline Any cephalosporin & 32 \\
Cefazolin & 12 \\
Gentamicin/tobramycin & 11 \\
Ampicillin/amoxicillin & 10 \\
Cefoxitin & 8 \\
Clindamycin & 6 \\
Ticarcillin & 6 \\
Sulfamethoxazole/ & 4 \\
trimethoprim & 4 \\
Erythromycin & \\
* Many of the 46 patients received more than one antimicrobial.
\end{tabular}

Diarrhea was defined as the occurrence of liquid stools or more than four bowel movements per day for at least three days. All patients in the study were judged moderately or severely ill, or unresponsive to supportive therapy (patients with mild illness as judged by their physicians were treated supportively, and not entered into the study). Stools were tested for the presence of the cytotoxin (toxin B) of C. difficile using fibroblast cell cultures [13], and were cultured anaerobically for $C$. difficile using cycloserine-cefoxitin-fructose agar [14]. All patients in the study had antibioticassociated diarrhea plus at least one stool specimen that demonstrated both C. difficile and its cytotoxin. Patients meeting these criteria were further subdivided into two groups. In the first, patients with endoscopic evidence of colitis were considered to have defi- nite colitis. The second group consisted of all other patients with diarrhea who had stools positive for the organism and toxin B; they were considered to have probable colitis (others might prefer that this group be designated $C$. difficile diarrhea). Patients were assigned (according to a table of random numbers) to treatment with vancomycin in a dose of either $125 \mathrm{mg}$ or $500 \mathrm{mg}$ given orally four times daily, and the physicians were aware of which regimen their patients received. Infants were treated orally with either 125 or $500 \mathrm{mg} / 1.73 \mathrm{~m}^{2}$ body surface area every six hours. Of 56 patients entered into the study, 10 were later excluded from the analysis by one of the investigaturs (who was unaware of the outcome of treatment) because of nonadherence to the protocol (two), lack of substantiation of the diagnosis (six), or death within 48 hours (two) because of an underlying disease (i.e., not due to diarrhea or colitis). Four of 28 patients treated with $500 \mathrm{mg} /$ day of vancomycin, and six of 28 patients treated with $2.0 \mathrm{~g} /$ day were excluded from the study; one patient in each group was excluded because of death within the first 48 hours. No patient had ileus, toxic megacolon, or impending perforation. In no case was it necessary to treat a patient with a parenteral antimicrobial agent for diarrhea because they were unable to receive oral vancomycin, but in a few cases vancomycin had to be administered through a nasogastric tube, which was clamped intermittently when suction was being applied. When vancomycin was begun, the antimicrobial regimen thought to have precipitated the diarrhea was either discontinued or replaced by an alternative regimen. No patients received antiperistaltic agents or other symptomatic treatment for diarrhea while receiving vancomycin, but fluids and electrolytes were replaced as needed. Diarrhea was considered to have ceased either when patients stated their bowel function was normal, or when they were having three or fewer movements a day and their stools were semi-formed. Patients whose diarrhea ceased within seven days after vancomycin was begun were considered to have a good response; patients whose diarrhea ceased but after seven days of treatment were considered simply to have responded.

\section{RESULTS}

Table I characterizes and compares the 46 patients retained in the study. Eighteen (39 percent) had probable $C$. difficile colitis and 28 (61 percent of the treated patients) had definite C. difficile colitis; all of the latter patients had endoscopically proven pseudomembranous colitis. In fact, all patients who underwent endoscopy had definile colitis. Twenty-four (52 percent) received the low dose of vancomycin $(500 \mathrm{mg} /$ day) and 22 ( 48 percent) received the high dose $(2.0 \mathrm{~g} /$ day). There were no statistically significant differences in the distribution of patients given the two dosage regimens in the groups in Table I ( $p>0.05$ ).

Table II compares other characteristics of the study groups. All but one of the patients were adults; the mean ages of the two groups were 56 (low dose) and 52 years (high dose). One infant with probable colitis was entered into the study and responded well to treatment (20 mg vancomycin given four times a day). This was the equivalent of the $125-\mathrm{mg}$ dose (based upon body surface area). The mean number of antibiotics received in the hospital per patient prior to onset of diarrhea, the number who received cancer chemo- 


\begin{tabular}{|c|c|c|c|c|}
\hline Diagnosis & $\begin{array}{l}\text { Daily Dose } \\
\text { of Vancomycin }\end{array}$ & $\begin{array}{l}\text { Number of Responses } \\
\text { at One Week } \\
\text { (percent) }\end{array}$ & $\begin{array}{l}\text { Number of Responses } \\
\text { after One Week } \\
\text { (percent) }\end{array}$ & $\begin{array}{c}\text { Total } \\
\text { Patients }\end{array}$ \\
\hline $\begin{array}{l}\text { Probable colitis } \\
\text { Subtotal }\end{array}$ & $\begin{array}{l}0.5 \mathrm{~g} \\
2.0 \mathrm{~g}\end{array}$ & $\begin{array}{l}8(72.7)^{*} \\
7(100)^{*} \\
15(83.3)\end{array}$ & $\begin{array}{c}3(27.3) \\
0- \\
3(16.7)\end{array}$ & $\begin{array}{l}11 \\
7 \\
18\end{array}$ \\
\hline $\begin{array}{l}\text { Definite colitis } \\
\text { Subtotal }\end{array}$ & $\begin{array}{l}0.5 \mathrm{~g} \\
2.0 \mathrm{~g}\end{array}$ & $\begin{array}{l}13(100)^{\dagger} \\
14(93.3)^{\dagger} \\
27(96.4)\end{array}$ & $\begin{array}{l}0- \\
1(6.7) \\
1(3.6)\end{array}$ & $\begin{array}{l}13 \\
15 \\
28\end{array}$ \\
\hline Both colitis groups & $\begin{array}{l}0.5 \mathrm{~g} \\
2.0 \mathrm{~g}\end{array}$ & $\begin{array}{l}21(87.5) \ddagger \\
21(95.4)^{\ddagger}\end{array}$ & $\begin{array}{l}3(12.5) \\
1(4.6)\end{array}$ & $\begin{array}{l}24 \\
22\end{array}$ \\
\hline Total patients & - & $42(91.3)$ & $4(8.7)$ & 46 \\
\hline
\end{tabular}

$x^{2}=3.0, p>0.05$

$x^{2}=1.04, p$

therapy, and the number who had serious underlying diseases, abdominal surgery, or intra-abdominal diseases did not differ significantly between the two groups. On the basis of these data, the two dosage groups were judged to be comparable. The antibiotics received prior to diarrhea are shown in Table III. Parenteral cephalosporins were most often implicated, and there were no significant differences in specific antibiotics between the two groups.

The responses to treatment with vancomycin by diagnostic group and by dosage regimen are summarized in Table IV. Overall, 91 percent of patients had a good response to therapy, with cessation of diarrhea within one week (Figure 1). There were no treatment failures. All patients improved and responded with cessation of diarrhea by 12 days. There were no significant differences in response rates according to the dosage regimen. The good response rate for definite antibiotic-associated colitis was 96 percent, and the rate was 83 percent for probable antibiotic-associated colitis. This difference was not statistically significant $\left(\chi^{2}=\right.$ $2.25 ; \mathrm{p}>0.05$ ). In subsequent analyses, these two categories have been grouped together.

As shown in Table V, the mean duration of abdominal pain after the start of therapy for all patients was $2.5 \pm 1.0$ (SE) days, and the mean duration of diarrhea after treatment was $4.1 \pm 1.6$ (SE) days, with a range of two to 12 days. Patients who received the lower dose of vancomycin had a slightly more rapid resolution of both pain and diarrhea, as shown for diarrhea in Figure 1 , but the differences were neither statistically nor clinically significant.

Because it was our clinical impression that elderly patients with antibiotic-associated colitis tend to have a more severe illness than do young patients, the effect of dose of vancomycin upon the rapidity of resolution of diarrhea for patients 60 years of age or less was compared with that of patients greater than 60 years of age. There was no significant difference in the rapidity of cessation of diarrhea in patients over 60 years who received the low dose of vancomycin (mean of 3.6 days) as compared with the high dose (mean 3.4 days). In fact, both means in patients over 60 were lower than the means for all patients, 4.1 days (Table V). Thus, it was not possible to confirm our subjective clinical impression that the disease was more severe in the elder-

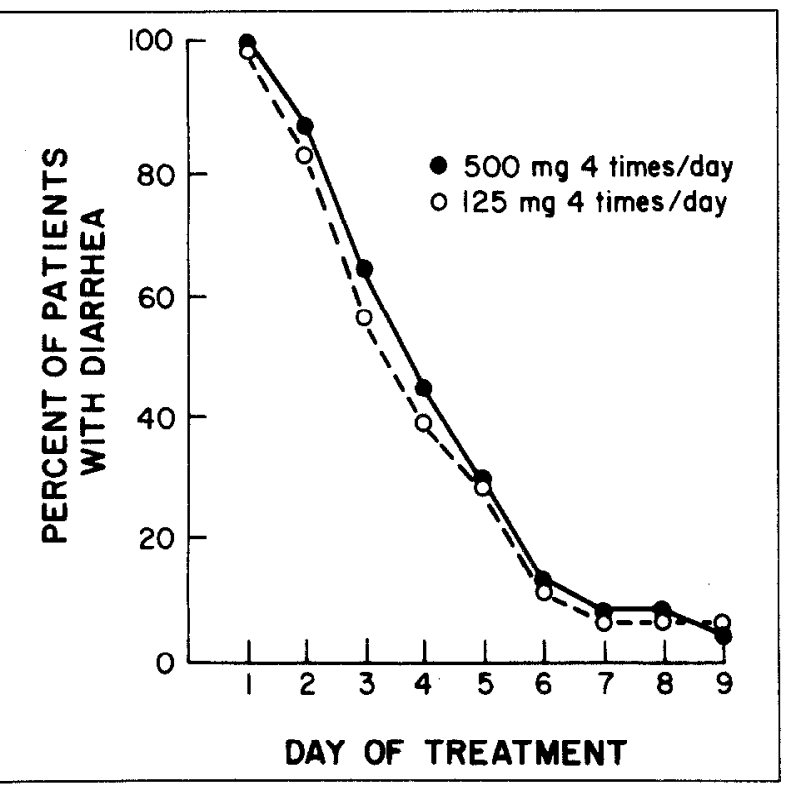

Figure 1. Cessation of diarrhea (rate) after institution of therapy with oral vancomycin.

\begin{tabular}{|lccc}
\hline $\begin{array}{l}\text { TABLE V } \\
\text { Duration of Symptoms after Start of Treatment (Mean } \pm \\
\text { SE in Days) }\end{array}$ \\
\hline Daily Dose & Number & Abdominal Pain & Diarrhea \\
\hline $0.5 \mathrm{~g}$ & 24 & $2.1 \pm 0.9$ & $3.8 \pm 1.4$ \\
$2.0 \mathrm{~g}$ & 22 & $2.7 \pm 1.5$ & $4.3 \pm 1.8$ \\
Total & 46 & $2.5 \pm 1.0$ & $4.1 \pm 1.6$ \\
\hline
\end{tabular}

ly, using criteria such as height of fever, number of stools a day, and so forth. Neither were there any objective or subjective differences in severity of the diarrhea in the two dosage groups. There were not enough patients with severe diarrhea in this study to permit separate analysis, but there did not appear to be a slower response in patients with profuse diarrhea and more severe illness.

Most patients were treated with vancomycin for about 10 days, with a range of five to 15 days. The duration of therapy was decided by the medical staff 


\section{TABLE VI}

Duration of Therapy with Vancomycin in Days

\begin{tabular}{lcc}
\hline & $0.5 \mathrm{~g} /$ Day & $\mathbf{2 . 0 \mathrm { g } / \text { Day }}$ \\
\hline Mean & 10.6 & 10.1 \\
Range & $7-12$ & $5-15$ \\
\hline
\end{tabular}

primarily responsible for the care of these patients, and based upon their clinical responses. There were no significant differences in the duration of therapy with vancomycin in the two groups, as shown in Table VI. This equivalence in duration of therapy further supports the equal efficacy of the two regimens. Four patients (all women) in this study were treated for more than 10 days with oral vancomycin because of a slow response to the drug. Three had received the low dose and one had received the high dose. Two of the women had underlying chronic inflammatory bowel diseases, and the other one had diabetes mellitus with a history of chronic diarrhea. These underlying diseases may have contributed to prolongation of diarrhea.

Nineteen patients, all of whom were asymptomatic, were available for follow-up studies and had stool cultures performed two to six weeks after discontinuation of vancomycin. There were no significant differences in the post-treatment carriage rates with the two regimens. Four of nine patients who received the $125-\mathrm{mg}$ dose and six of 10 who received the $500-\mathrm{mg}$ dose had positive results of stool cultures in convalescence. The overall rate of positive stool cultures in asymptomatic patients available for post-treatment culture was 56 percent (10 of 19). Of the 10 patients who were shown to be post-treatment carriers of $C$. difficile, five ( 50 percent) developed a recurrence of their disease within the first few months following the completion of therapy with vancomycin, usually spontaneously (no antibiotics administered). Post-treatment culture specimens had not been obtained from four other persons who experienced a recurrence. A total of nine recurrences developed in the 46 patients (20 percent). Most patients who had a recurrence did so within six weeks after the discontinuation of therapy. Five patients who developed a recurrence had received the $125-\mathrm{mg}$ dose and four had received the 500-mg dose. Overall, the rate of symptomatic recurrence was 20 percent, and the difference in frequency with the low- (20.8 percent) and the high-dose (18.9 percent) regimens was not statistically significant. Vancomycin-resistant (minimal inhibitory concentration greater than $16 \mu \mathrm{g}$ / $\mathrm{ml}) C$. difficile isolates were not detected during relapses. Patients with relapses were not re-entered into the study, but were re-treated with a short course of oral vancomycin in a dosage chosen by their physician. All responded promptly to this measure and there were no further recurrences.

Vancomycin was tolerated well by all patients, and none showed any evidence of systemic toxicity.

\section{COMMENTS}

This study did not show a significant difference in the efficacy of total daily oral doses of $500 \mathrm{mg}$ and $2,000 \mathrm{mg}$ of vancomycin given in four divided doses in the therapy of adults with antibiotic-associated diarrhea and/or colitis caused by $C$. difficile. There were no treatment failures with either dose. As measured by the rapidity of cessation of abdominal pain (mean 2.5 days) or diarrhea (mean 4.1 days), the rate of response by seven days (about 90 percent), the frequency of side effects (essentially none), the duration of therapy (usually about 10 days), the frequency of positive cultures after treatment (mean of 56 percent in those available for post-treatment cultures), and the rate of recurrences or relapses ( 20 percent), no significant differences were noted between the two dosage regimens. Although almost 10 percent of patients continued to have diarrhea for more than seven days after therapy was started, the condition of all patients had clearly improved within one week. Thus, diarrhea persisting for seven days or more after therapy with vancomycin was begun did not by itself indicate a failure of treatment.

Although these findings do not prove equivalence of the two regimens, they are consistent with predictions of equivalence based upon: (1) the minimal systemic absorption of vancomycin when it is administered orally, (2) predicted stool concentrations $(100 \mu \mathrm{g} / \mathrm{ml}$ or more) with the lower dose even when there is diarrhea amounting to 5 liters/day, and (3) the fact that in vitro concentrations of vancomycin equal to or less than 5 $\mu \mathrm{g} / \mathrm{ml}$ are sufficient to inhibit $C$. difficile isolates obtained from patients with pseudomembranous colitis $[14,15]$. Vancomycin-resistant isolates of $C$. difficile have never been detected. Although stool concentrations of vancomycin were not measured in this study, it is likely the concentrations achieved in stools using the lower dose were many times (at least 20) greater than those required for inhibition of $C$. difficile. Thus, one advantage of vancomycin over less expensive alternative therapies such as metronidazole and bacitracin relates to the fact that resistant isolates of both of the latter have been detected $[7,16]$.

In interpreting our results, there are two points that should be noted. First, it is possible that the higher (or less likely the lower) dose is actually better, but that its superiority was masked because there were too few patients in the study. When the observed response rates (Figure 1) and their variability are considered, detection of a clinically significant difference between the two groups in frequency of diarrhea at four or seven days would have required a study involving approximately 200 or 1,000 patients, respectively [17]. Such a study is unlikely to come from a single institution. This theoretical consideration as well as our observed results demonstrating no clinically significant differences in responses with these doses will probably discourage any further attempt to conduct a multicenter study on the issue. Second, it is possible that there may be a difference between the two regimens that is evident only with very "sick" or "toxic" patients. Patients in this study were judged to be moderately or severely ill, but patients were not stratified for severity of illness prior to entry into the study. In retrospect, only a small number (five to 10) of our patients could be considered severely ill. If there is reason to question the efficacy of the lower dose in severely ill patients, the higher dose of vancomycin could be used, and is in our opinion preferred over metronidazole in this setting. However, severe illness is not a problem with the vast majority of patients with C. difficile colitis, especially if the diagnosis is made 
early in the disease. Since completing this study, we have used the lower dose preferentially at the University of Michigan Hospitals, and have not encountered any treatment failures with the drug.

From the standpoint of cost, the lower dose of vancomycin offers some obvious advantages. The current local acquisition cost for the vancomycin capsules available for oral treatment in a dosage of $125 \mathrm{mg}$ four times daily for seven days is $\$ 111$; for $500 \mathrm{mg}$ four times daily it is $\$ 444$. Although little or no vancomycin is absorbed when it is given orally, even in the presence of colitis $[1,3,18]$, therapeutic serum concentrations have been detected in patients with severe renal failure [19]. This risk, which is mostly a theoretical one, is further reduced when the lower dose $(125 \mathrm{mg})$ is used and it is therefore preferred in patients with renal failure.

For the patient with mild or moderately severe $C$ difficile colitis in whom specific treatment is desirable, it is likely, although still speculative, that lowdose vancomycin $(0.5 \mathrm{~g} /$ day $)$ is as effective as metronidazole [5]. It is also potentially less toxic [20]. Cost considerations favor metronidazole for treatment of these patients. The local acquisition cost for metronidazole ( $250 \mathrm{mg}$ orally four times daily) is only $\$ 3$. For more seriously ill patients, oral vancomycin is still the drug of choice in our opinion because of possible resistance of the organism to metronidazole or bacitracin and because metronidazole may be absorbed completely from the small intestines of patients with impending ileus. Some would recommend the addition of intravenous metronidazole and/or vancomycin to the regimen in critically ill patients with ileus. For those unable to tolerate metronidazole because of real or potential toxicity, low-dose vancomycin is preferred for adults, and bacitracin is an alternate. However, similar toxicity was seen with vancomycin and metronidazole in the study of Teasley et al [5]. Since both post-treatment intestinal carriage of $C$. difficile and relapses or recurrences of $C$. difficile colitis have been observed with all forms of therapy (vancomycin, metronidazole, or bacitracin), and at about the same frequency [16], these factors do not provide good reasons to choose between the regimens.

Other investigational drugs that are active against C. difficile, such as teicoplanin and daptomycin, may have practical advantages over vancomycin or metronidazole, but it is unlikely they will be superior in effectiveness. Further studies are needed with these potentially useful agents.

\section{REFERENCES}

1. Bartlett JG, Chang T, Taylor NS, Onderdonk AB: Colitis induced by Clostridium difficile. Rev Infect Dis 1979; 1: 370-378.

2. Fekety R: Recent advances in management of bacterial diarrhea. Rev Infect Dis 1983: 5: 246-257.

3. Silva J, Batts DH, Fekety R, Plouffe JF, Rifkin GD, Baird I: Treatment of Clostridi um difficile colitis and diarrhea with vancomycin. Am J Med 1981; 71: 815-822. 4. Fekety R: Vancomycin. In: Mandell G, Douglas G, Bennett J, eds. Principles and practice of infectious diseases, 2nd ed. New York: John Wiley, 1985; 232-235. 5. Teasley DG, Gerding DN, Olson MM, et al: Prospective randomised trial of metronidazole versus vancomycin for Clostridium difficile associated diarrhea and colitis. Lancet 1983; II: 1043-1046.

6. Dzink J, Bartiett JG: In vitro susceptibility of Clostridium difficile isolates from patients with antibiotic-associated diarrhea or colitis. Antimicrob Agents Chemother 1980; 17: 695-698.

7. Saginur R, Hawley CR, Bartlett JG: Colitis associated with metronidazole therapy. J Infect Dis 1980; 141: 772-774

8. Fekety R: Recent advances in management of bacterial diarrhea. Rev infect Dis 1983; 2: 246-257

9. Dudley MN, MCLaughlin JC, Carrington G, Frick J, Nightingale $\mathrm{CH}$, Quintiliani R: Oral bacitracin vs. vancomycin therapy for Clostridium difficile induced diarrhea. A randomized double-blind trial. Arch Intern Med 1986; 146: 1101-1104.

10. Young GP, Ward PB, Bayley N, et al: Antibiotic-associated colitis due to Clostridium difficile: double-blind comparison of vancomycin with bacitracin. Gastroenterology 1985; 89: 1038-1045.

11. Geraci JE, Heilman FR, Nichols DR, et al: Some laboratory and clinical experiences with a new antibiotic. Proc Staff Meet Mayo Clin 1956; 31: 564-571.

12. Keighley MRB, Burdon DW, Arabi $Y$, et al: Randomised controlled trial of vancomycin for pseudomembranous colitis and postoperative diarrhea. $\mathrm{Br}$ Med $J$ 1978: 2 : 1667-1671.

13. Cudmore MA, Silva J, Fekety R, et al: Clostridium difficile colitis associated with cancer chemotherapy. Arch Intern Med 1982; 142: 333-335.

14. George WL, Sutter VL, Citron D. Finegold SM: Selective and differential medium for isolation of Clostridium difficile. J Clin Microbiol 1979; 9: 214-219.

15. Fekety $R$, Silva J, Toshniwal $R$, et al: Antibiotic-associated colitis: effects of antibiotics on Clostridium difficile and the disease in hamsters. Rev Infect Dis 1979; 1: $386-396$

16. Fekety R: Antibiotic-associated colitis. in: Mandell G, Douglas G. Bennett J, eds. Principles and practice of infectious diseases, 2nd ed. New York: John Wiley, 1985 $655-660$

17. Detsky AS, Sackett DL: When was a negative clinical trial big cnough? Arch Intern Med 1985; 145: 709-712.

18. Tedesco FJ, Markham M, Gurwith DC, Bartlett JG: Oral vancomycin for antibiotic associated pseudomembranous colitis. Lancet 1978; II: 226-228.

19. Spitzer PG, Eliopoulis GM: Systemic absorption of enteral vancomycin in a patient with pseudomembranous colitis. Ann Intern Med 1984; 100: 523-534. 20. Fincgold SM: Metronidazole. In: Mandell G. Douglas G, Bennett J, eds. Principles and practice of infectious diseases, 2nd ed. New York: John Wiley, 1985; 220 224. 